\title{
Investigation of Complex Structural Designing of Mobile Facilities for Shipbuilding in Lithuanian Sea Region
}

\author{
Tadas ASTRAUSKAS*, Michail SAMOFALOV** \\ *Klaipéda University, Bijūnu 17, LT-91225 Klaipéda, Lithuania, E-mail: tadasa123@gmail.com \\ **Klaipéda University, Bijūnu 17, LT-91225 Klaipéda, Lithuania, E-mail: michail.samofalov@ku.lt \\ cross ref http://dx.doi.org/10.5755/j02.mech.28740
}

\section{Introduction}

In Lithuanian shipyards, main manufacturing is organized inside covered workshops. On open sites of the territory, the assembling of ship hulls is being carried out. The open areas are subjected to changeable climatic conditions, which reduce the efficiency of the production process [1-2]. In our paper, it is proposed to cover by mobile moving structures the shipyard open territory, which was built in Klaipeda (Lithuania, the EU) in 1952 (Figs. 1 and 2).

Some engineering problems of dynamics and stability can be found in scientific research [3-5]. Nevertheless, designing techniques for original facilities are created depending on specific conditions and particularities of a new problem [6-7]. In case of movement problems, different boundary conditions and limit states of structures have the especially important influence [8-12].

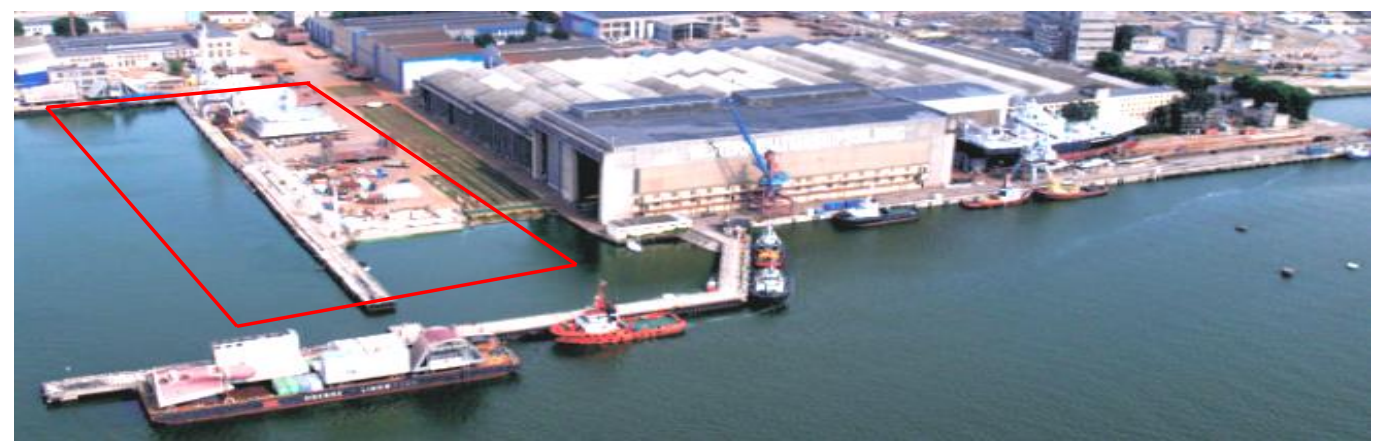

Fig. 1 A general view on the seaport shipbuilding (with the marked open site) in Klaipeda, Lithuania, the EU

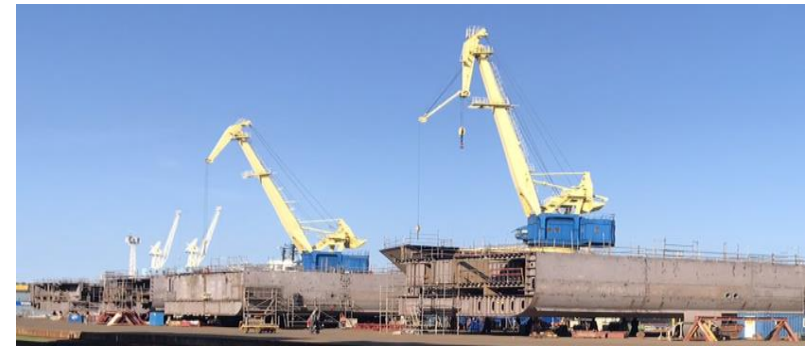

Fig. 2 Shipbuilding open site

By the presented research, the variants of the mobile moving facility have been investigated. Two types of steel frames have been considered: trussed and continuous. A rational solution has been chosen, taking into account the climatic features of our sea region, the valid design codes and the technical capabilities of the shipyard.

For solving of complex problems of statics, kinematics, dynamics, stability and design issues, the finite element method (FEM) with engineering applications has been used. All calculation schemes have been modelled on the elastic foundation [13]. This methodology is intended for the development of designing methods of mobile industrial structures.

\section{Main concept and data of the structural models}

According to technical specifications, which had been received from the shipyard: maximal sectional di- mensions of a ship block are $32 \times 16 \mathrm{~m}$ and of the unlimited length; dimensions of an assembling volume is max $35 \times 19 \times 30 \mathrm{~m}(b \times h \times l)$; outside dimensions of the facility are $40 \times 23 \times 30 \mathrm{~m}$ (Fig. 3). The S355 steel grade is adopted (Eurocode 3 ). In the preliminary calculation of one transverse frame, the following cross sections have been accepted: chords are from hollow sections $180 \times 180 \times 8 \mathrm{~mm}$; lattice $-140 \times 140 \times 6 \mathrm{~mm}$. Continuous frame was of Isection: thickness of the flange is $10 \mathrm{~mm}$; width of the flange $-400 \mathrm{~mm}$; thickness of the web $-10 \mathrm{~mm}$; variable cross-sectional height is from 0.5 to $2.5 \mathrm{~m}$. Parts of the frame are connected by flange joints, thin-walled cross sections are strengthening by stiffeners. A cover of the mobile facility is made from a very light, temperature and deformation resistance, tensioned PVC membrane [14]. The facility is covered by the tent from all sides, but at the ends of the facility it is possible to partially remove this tent and create gates, so the mobile structure could move over a ship block.

Transversal frames of the facility are arranged by the same step of $6.0 \mathrm{~m}$. The frames are connected by a system of flexible cable braces [15-17], diameter of which is $18 \mathrm{~mm}$, and of longitudinal braces of the hollow section $120 \times 120 \times 6 \mathrm{~mm}$. During the construction of the facility, the cable braces will have been pre-tensioned by $3.0 \mathrm{kN}$ on the roof and $1.0 \mathrm{kN}$ on the walls. The following values for elastic supports (springs) [18] are defined: across the facility it is $7.0 \mathrm{MN} / \mathrm{m}$; vertically $-36.0 \mathrm{MN} / \mathrm{m}$; lengthwise $14.2 \mathrm{MN} / \mathrm{m}$. 


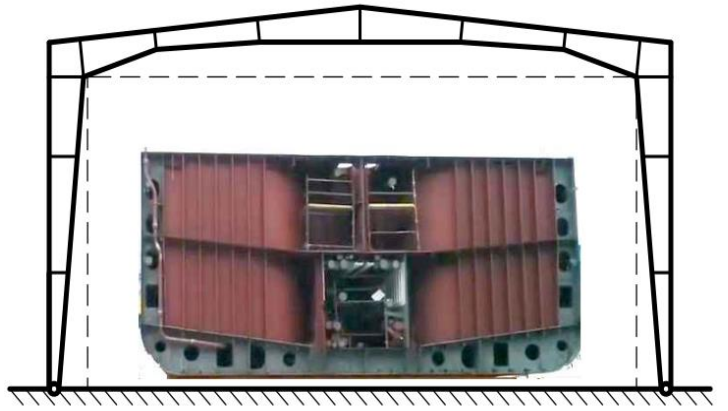

Fig. 3 The mobile frame over a ship block

The following actions are specified according to the design codes and climatological data: dead load of structural weight and weight of technological equipment; wind in 8 different directions, $32 \mathrm{~m} / \mathrm{s}$; snow, $1.6 \mathrm{kPa}$. As it was already mentioned, under the action of wind, various configurations of the facility have been considered: facility completely covered by the tent or partially covered: with the open ends of the walls. Relative vertical displacements for the frame beam are taken into account $40 \cdot 10^{3} / 300=$ $133 \mathrm{~mm}$, horizontal displacements for the columns inplane and out-of-plane of the frame are limited by $21 \cdot 10^{3} / 300=70 \mathrm{~mm}$. In total 149 load combinations have been created.

The facility should be used for 50 years; the reliability class is RC3 (Eurocode). In dynamic analysis, the longitudinal direction is defined for inertia action, simulating braking [19]. It is assumed, that the maximum speed is $0.50 \mathrm{~m} / \mathrm{s}$, time of the braking is $5.0 \mathrm{~s}$, and the acceleration is $0.10 \mathrm{~m} / \mathrm{s}^{2}$. The movement of the frames is possible symmetrically forward or backward. An emergency case was also calculated, while one side of the frame has stopped, but the other continues to move (Fig. 4).

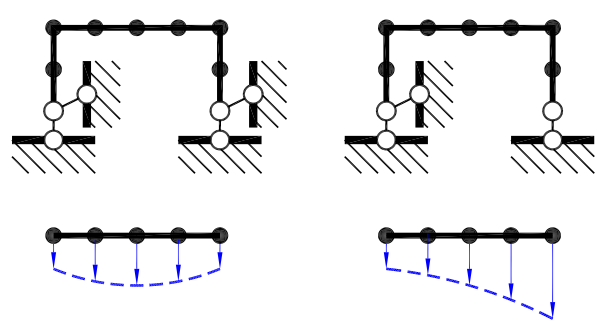

Fig. 4 Movement schemes of the mobile frame

The mobile facility is moved by electric motors on rails along the side of the production workshop, from which the blocks of ships are slipped on transverse rails and will be assembled under the mobile structures (Fig. 5).

There can be several mobile facilities. The assembled superblock is moved to the nearest area, where it is connected to the hull of the ship under construction. Then the hull is moved to the barge, which transports the new ship to the port of destination by sea.

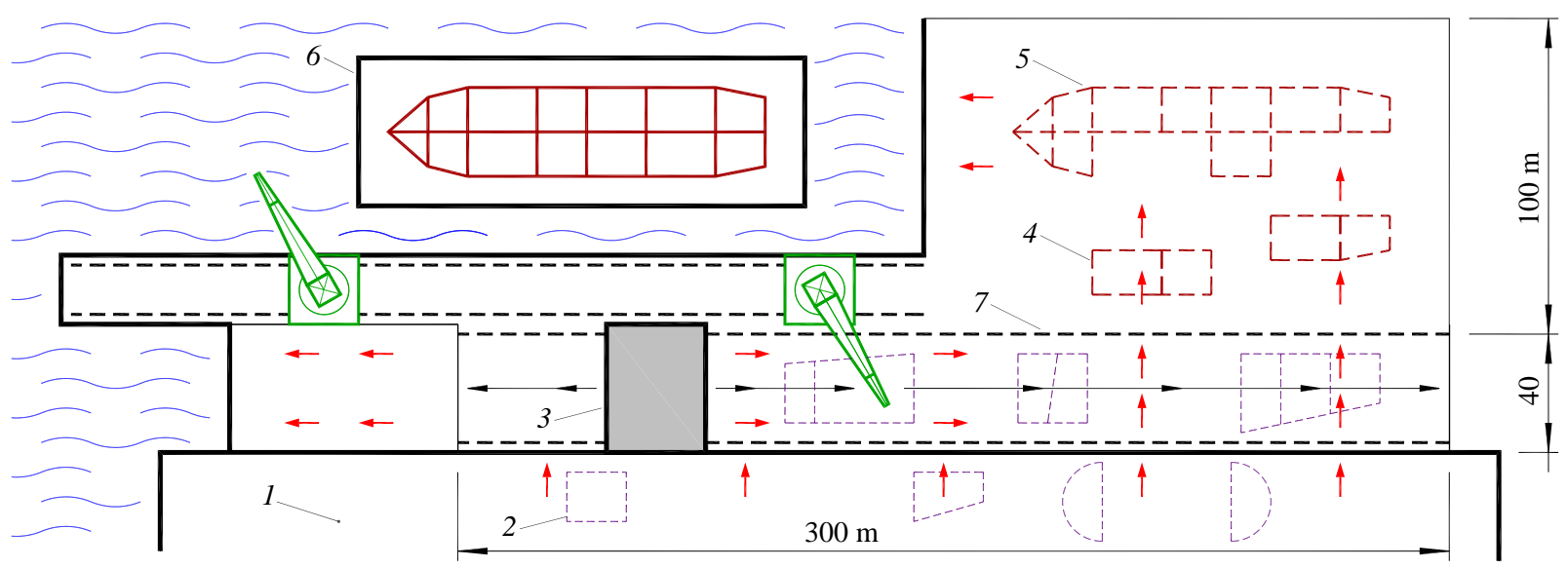

Fig. 5 The scheme of the open area for assembling: 1 - factory; 2 - block; 3 - mobile facility; 4 - superblock; 5 - ship hull; 6 - barge; 7 - railway

Main assumptions in calculations:

- $\quad$ steel deforms elastically;

- the transverse frames are connected by braces, which restrict the torsion of the facility [20];

- the movement of the facility is set according to an example [21];

- both global and local stability are taken into account;

- optimization is carried out, taking into account the requirements of design codes.

For the FEM calculations, three different design schemes from various types of finite elements (FE) have been created (Fig. 7):

1) of trussed FE type, named "Truss 1D";

2) of continuous bending FE type, named "Beam 1D";

3 ) of continuous plate FE type, named "Plate 2D".

These names of schemes are often used later.

\section{Algorithm}

For calculation of the mobile facility, a special algorithm has been prepared. It consists of three main stages (Fig. 6).

At the first stage of analysis, three calculation schemes of one transversal frame have been created. After the calculations, the given results were analyzed: displacement, internal forces, stability etc.

At the second stage, all frames have been joined by braces. The mobile facility was completed. The results were checked again, but this time - for all frames and for the system of braces also. Next, optimization of groups of cross sections for all structural members was performed. For the continuous frame Plate 2D, the maximal stresses and phenomenon of local buckling were checked. 


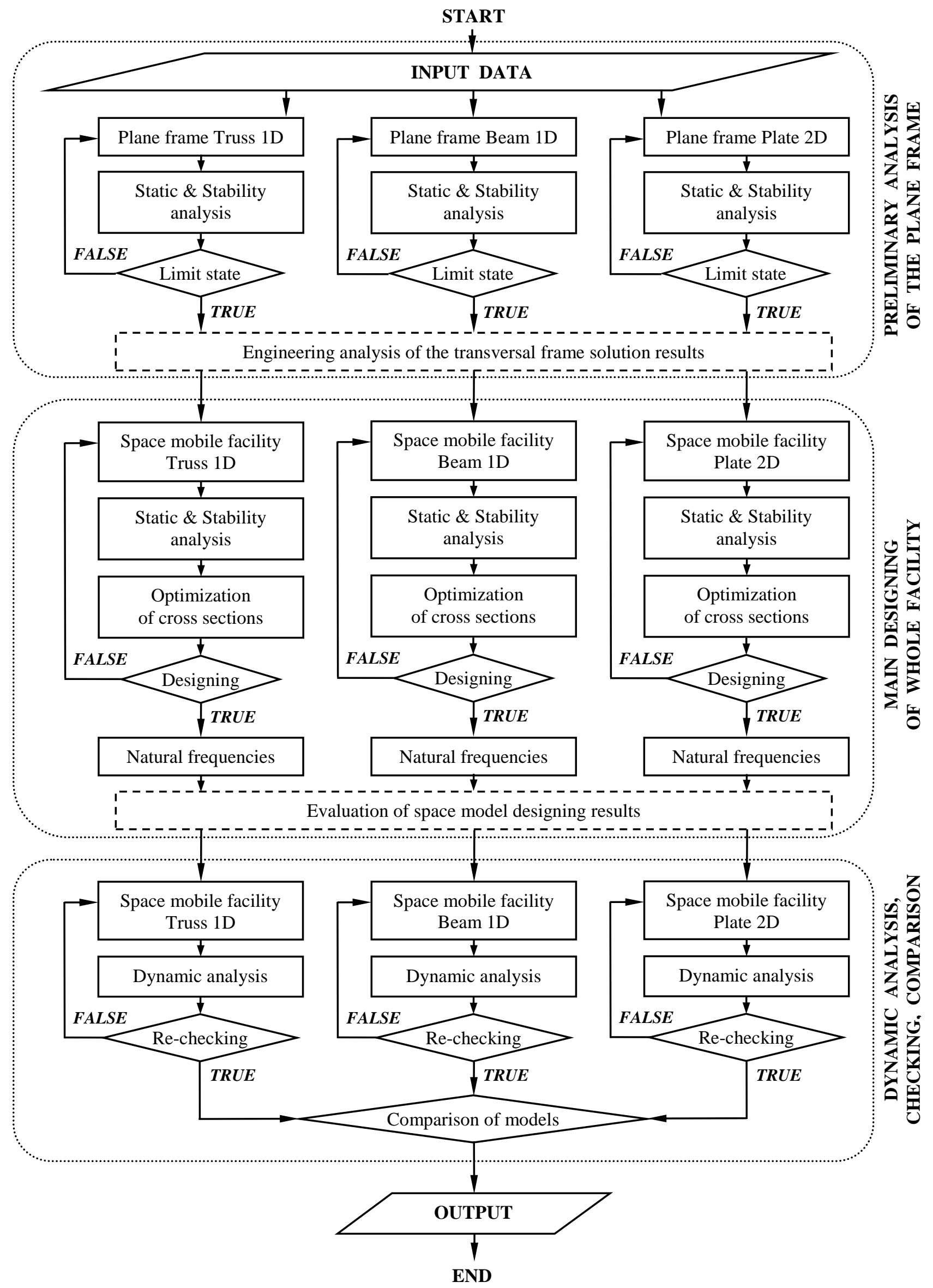

Fig. 6 The structural analysis algorithm of different types of the frames 


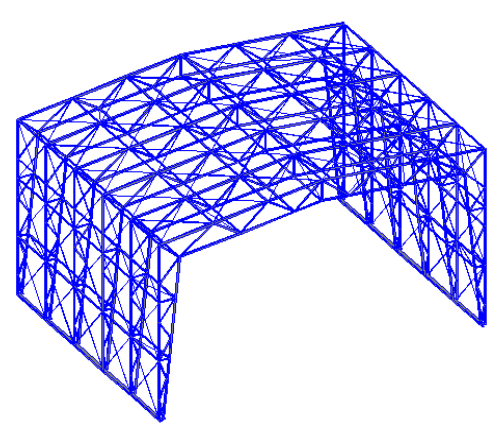

a

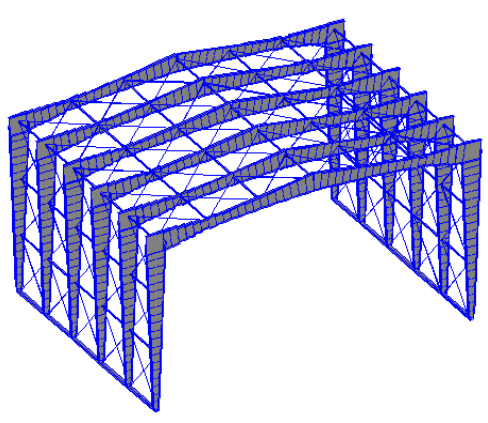

b

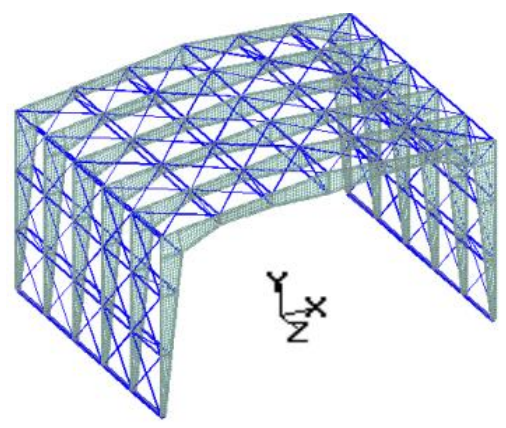

C

Fig. 7 A general views of FEM models: a - Truss 1D; b - Beam 1D; c - Plate 2D

At the third stage, the dynamic analysis was carried out: the action of inertia forces on the structure during braking was simulated. Taking into account the obtained results, the design models were re-checked.

Finally, we compared the calculation results of three different FEM models and chose the most appropriate one. During the last calculation, all information, which is necessary for structural designing, was obtained: support reactions, internal forces, buckling factors, frequencies, etc.

\section{Preliminary analysis of plane frames}

The first scheme of the transversal frame was created from one-dimensional FEs of truss, marked Truss 1D. The continuous section frame was modelled from bending one-dimensional FEs and, due to the variable cross section, was divided into FEs of $1 \mathrm{~m}$ length, further Beam 1D. For analysis of local deformation, another continuous frame was simulated from two-dimensional FEs and was labeled Plate 2D. For three different variants of the transversal frame, the loads and supports were analogically set (Fig. 8).

After the linear static analysis, deformed shapes of the schemes (displacement values relative to the limit values) were similar ones for all variants (Table 1): vertical displacements are different by $9-11 \%$, horizontal ones - by
$2-5 \%$.

Table 1

Primary calculations at the first stage

\begin{tabular}{|c|c|c|c|c|}
\hline \multirow{2}{*}{$\begin{array}{c}\text { Struc- } \\
\text { ture/shape } \\
\text { mode/ }\end{array}$} & \multirow{2}{*}{$\begin{array}{l}\text { Buck- } \\
\text { ling } \\
\text { factor }\end{array}$} & \multicolumn{2}{|c|}{ Relative displacement } & \multirow{2}{*}{$\begin{array}{c}\text { Frame } \\
\text { weight, } \\
\%\end{array}$} \\
\hline & & Vert. & Horz. & \\
\hline Truss 1D /1/ & $3.27(\mathrm{G})$ & \multirow{3}{*}{0.48} & \multirow{3}{*}{0.82} & \multirow{3}{*}{100} \\
\hline Truss 1D /2/ & $4.57(\mathrm{G})$ & & & \\
\hline Truss 1D /3/ & $5.10(\mathrm{G})$ & & & \\
\hline Beam 1D /1/ & $8.53(\mathrm{G})$ & \multirow{3}{*}{0.57} & \multirow{3}{*}{0.87} & \multirow{3}{*}{122} \\
\hline Beam 1D /2/ & $12.1(\mathrm{G})$ & & & \\
\hline Beam 1D /3/ & $15.6(\mathrm{G})$ & & & \\
\hline Plate 2D /1/ & $0.85(\mathrm{~L})$ & \multirow{3}{*}{0.46} & \multirow{3}{*}{0.85} & \multirow{3}{*}{124} \\
\hline Plate 2D /2/ & $0.90(\mathrm{~L})$ & & & \\
\hline Plate 2D /3/ & $1.16(\mathrm{~L})$ & & & \\
\hline
\end{tabular}

Although the buckling shape modes are visually similar (Fig. 8), the critical values are different for all three transversal frames. The frame Truss 1D loses its stability, when the load is two times less, than the frame Beam 1D. The reason is lower stiffness of each structural member for a truss. The scheme Plate $2 \mathrm{D}$ is 10 times more sensitive than Beam 1D, because the plate FE model allows for the local buckling of the web in I-section. The most stressed zone of the frame is the joint between the beam and the column.

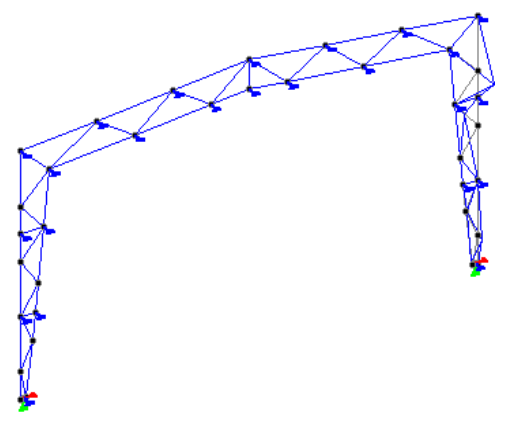

a

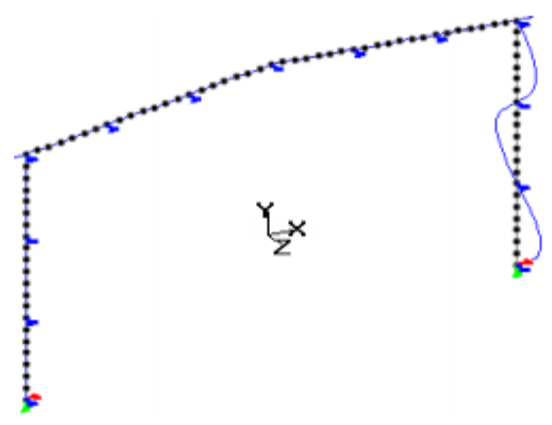

b

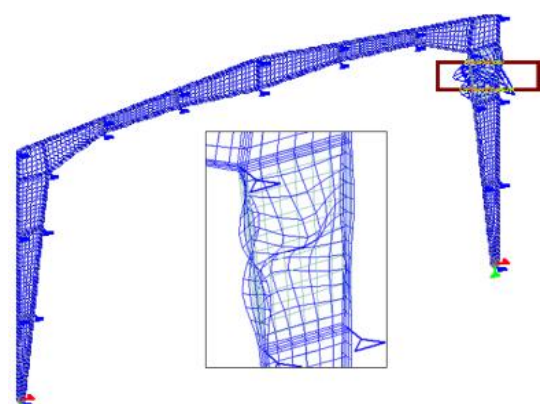

$\mathrm{c}$

Fig. 8 The first buckling mode shape of the FEM frame: a - Truss 1D; b-Beam 1D; $c$ - Plate 2D

Since the critical values 0.85 for the Plate $2 \mathrm{D}$ frame is less than 1.00 , the cross-sectional web thickness $10 \mathrm{~mm}$ was increased to $12 \mathrm{~mm}$. This modification has made frames Plate 2D and Beam 1D of $16 \%$ heaver.

Taking into account the results of the initial calculation, for the trussed frame the cross sections $180 \times 180 \times 8 \mathrm{~mm}$ of chords are decreased to $180 \times 180 \times 6 \mathrm{~mm}$, and the lattice - from $140 \times 140 \times 6 \mathrm{~mm}$ to
$120 \times 120 \times 6 \mathrm{~mm}$. The weight of the frame Truss 1D has been reduced by $18 \%$.

After testing and checking of all models of the transverse frame, the requirements of bearing capacity was satisfied. The shape modes of stability have not changed. The model Truss 1D has a valuable advantage in weight (Table 2). 
Table 2

Table 4

Calculations after improvement at the first stage

\begin{tabular}{|c|c|c|c|c|}
\hline \multirow{2}{*}{$\begin{array}{c}\text { Structure/shape } \\
\text { mode/ }\end{array}$} & \multirow{2}{*}{$\begin{array}{l}\text { Buckling } \\
\text { factor }\end{array}$} & \multicolumn{2}{|c|}{$\begin{array}{c}\text { Relative displace- } \\
\text { ment }\end{array}$} & \multirow{2}{*}{$\begin{array}{c}\text { Frame } \\
\text { weight, } \\
\%\end{array}$} \\
\hline & & Vert. & Horz. & \\
\hline Truss 1D /1/ & $2.71(\mathrm{G})$ & \multirow{3}{*}{0.56} & \multirow{3}{*}{0.93} & \multirow{3}{*}{82} \\
\hline Truss 1D /2/ & $3.72(\mathrm{G})$ & & & \\
\hline Truss 1D /3/ & $4.32(\mathrm{G})$ & & & \\
\hline Beam 1D /1/ & $10.1(\mathrm{G})$ & \multirow{3}{*}{0.54} & \multirow{3}{*}{0.81} & \multirow{3}{*}{142} \\
\hline Beam 1D /2/ & $10.2(\mathrm{G})$ & & & \\
\hline Beam 1D /3/ & $17.3(\mathrm{G})$ & & & \\
\hline Plate 2D /1/ & $1.56(\mathrm{~L})$ & \multirow{3}{*}{0.43} & \multirow{3}{*}{0.78} & \multirow{3}{*}{144} \\
\hline Plate 2D /2/ & $1.65(\mathrm{~L})$ & & & \\
\hline Plate 2D /3/ & $2.12(\mathrm{~L})$ & & & \\
\hline
\end{tabular}

\section{Main designing of the whole facility}

So, by connecting six frames by braces and forming a mobile facility, the problems of the second stage were calculated (Fig. 6). All structural members of such mechanical system have been presented as groups, based of cross-sectional area. After performing the optimization procedure, which allows applying the used engineering software (Staad.Pro), a rational cross section was selected for each group.

When searching for optimal solution, the best case was chosen: some cross sections of bars of the scheme Truss 1D were decreased, and some increased (Table 3). The cross sections of the frames Plate 2D and Beam 1D remained the same. It turned out, that due to the oblique wind, the diameter of flexible braces should be increased to $30 \mathrm{~mm}$. Tension forces remain the same. The cross sections of the longitudinal orthogonal braces decreased.

Table 3

Evaluation after optimization, the second stage

\begin{tabular}{|l|c|c|}
\hline \multicolumn{1}{|c|}{ Structural member } & Before & After \\
\hline Column outside chord & $180 \times 180 \times 6$ & $140 \times 140 \times 6$ \\
\hline Column inside chord & $180 \times 180 \times 6$ & $180 \times 180 \times 6$ \\
\hline Column lattice & $120 \times 120 \times 6$ & $100 \times 100 \times 5$ \\
\hline Beam upper chord & $180 \times 180 \times 6$ & $200 \times 200 \times 8$ \\
\hline Beam bottom chord & $180 \times 180 \times 6$ & $160 \times 160 \times 8$ \\
\hline Beam lattice & $120 \times 120 \times 6$ & $140 \times 140 \times 6$ \\
\hline Thickness of stiffeners & 12 & 11 \\
\hline Longitudinal braces & $120 \times 120 \times 6$ & $120 \times 120 \times 5$ \\
\hline Diameter of cable braces & 18 & 30 \\
\hline
\end{tabular}

The bearing capacity of the structural members is provided by requirements of design codes (Eurocode 3 ). As a result of the automatic selection of cross sections, the weight of the facility models decreased insignificantly, only by $2-4 \%$ (Table 4 ). After calculation of the general stability, the shape modes of the models were the same in comparison with the calculation of the single frames. Therefore, critical load factors were decreased significantly: for the space scheme Truss 1D - by $21-50 \%$, for Beam $1 \mathrm{D}$ - by $38-54 \%$, for Plate $2 \mathrm{D}-$ by $8-26 \%$. It is due to the changing of ideally rigid out-of-plane links to the braces with real stiffnesses. The natural frequencies and appropriate mode shapes for the facilities were also determined. For all three FEM models, the first two mode shapes are linear-bending (B), and the third is a torsional one $(\mathrm{T})(\mathrm{Ta}-$ ble 4).
The second stage calculations after optimization

\begin{tabular}{|c|c|c|c|c|c|}
\hline \multirow{2}{*}{$\begin{array}{c}\text { Struc- } \\
\text { ture/shape } \\
\text { mode/ }\end{array}$} & \multirow{2}{*}{$\begin{array}{l}\text { Buckling } \\
\text { factor }\end{array}$} & \multirow{2}{*}{$\begin{array}{l}\text { Frequency } \\
\text { value, } \mathrm{Hz}\end{array}$} & \multicolumn{2}{|c|}{$\begin{array}{c}\text { Relative } \\
\text { displacement }\end{array}$} & \multirow{2}{*}{$\begin{array}{c}\text { Frame } \\
\text { weight, } \\
\%\end{array}$} \\
\hline & & & Vert. & Horz. & \\
\hline Truss 1D /1/ & $2.14(\mathrm{G})$ & $1.41(\mathrm{~B})$ & \multirow{3}{*}{0.70} & \multirow{3}{*}{0.90} & \multirow{3}{*}{80} \\
\hline Truss 1D /2/ & $2.16(\mathrm{G})$ & $3.32(\mathrm{~B})$ & & & \\
\hline Truss 1D /3/ & $2.32(\mathrm{G})$ & $4.05(\mathrm{~T})$ & & & \\
\hline Beam 1D /1/ & $5.54(\mathrm{G})$ & $0.99(\mathrm{~B})$ & \multirow{3}{*}{0.83} & \multirow{3}{*}{0.96} & \multirow{3}{*}{138} \\
\hline Beam 1D /2/ & $6.29(\mathrm{G})$ & $1.53(\mathrm{~B})$ & & & \\
\hline Beam 1D /3/ & $7.97(\mathrm{G})$ & $1.90(\mathrm{~T})$ & & & \\
\hline Plate 2D /1/ & $1.43(\mathrm{~L})$ & $1.10(\mathrm{~B})$ & \multirow{3}{*}{0.60} & \multirow{3}{*}{0.87} & \multirow{3}{*}{140} \\
\hline Plate 2D /2/ & $1.48(\mathrm{~L})$ & $1.88(\mathrm{~B})$ & & & \\
\hline Plate 2D /3/ & $1.56(\mathrm{~L})$ & $2.21(\mathrm{~T})$ & & & \\
\hline
\end{tabular}

\section{Dynamic analysis and additional designing}

For the calculation models the acceleration was set, which appears in case of the braking or beginning of the movement of the facility. A separate accident case was also simulated, when one side of the frames has stopped, and other one continuous to move (Fig. 9).

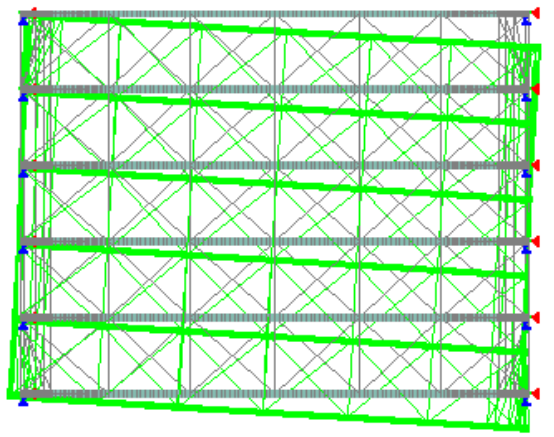

Fig. 9 Top view of deformation scheme Plate 2D, while one side is fixed

The values of the stresses and the stress state was checked in the model Plate 2D (Fig. 10). The dynamic action deflects three FEM models on approximately the same manner: the deformed schemes are similar.

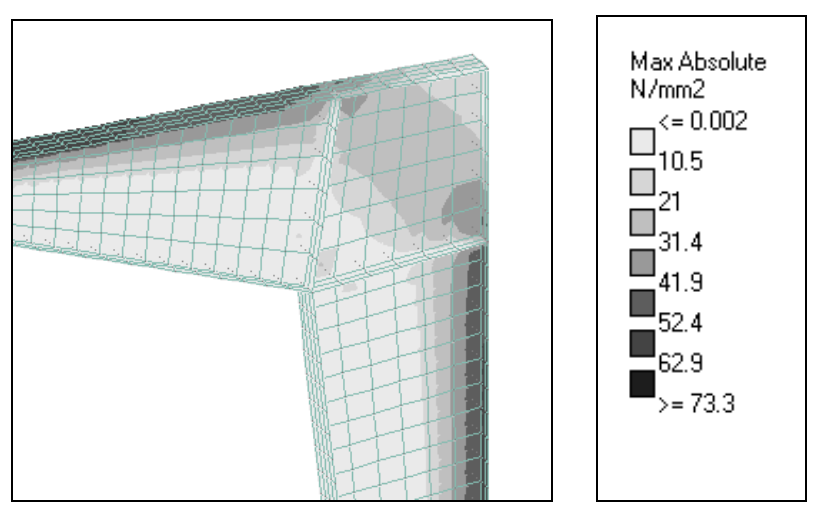

Fig. 10 The stress distribution in scheme Plate 2D at the column/beam joint

During the linear symmetrical moving forward or backward, internal forces of some structural members increased up to $7 \%$, in case of an oblique direction - up to $14 \%$. Nevertheless, after dynamic calculations, the cross sections of the frames were not generally changed. For 
oblique movement, another natural frequency appeared, which began to dominate: for scheme Truss 1D $-0.81(\mathrm{~T})$, 1.41(B), 3.68(T) Hz; for scheme Beam 1D - 0.52(T), 0.90(B), 1.28(T) Hz; for scheme Plate 2D - 0.46(T), 0.98(B), 1.93(T) Hz. So, more torsional shape modes appeared which were caused by the asymmetry of the boundary conditions of the facility.

\section{Generalisation of the results}

A preliminary comparison of the calculation results of the models was carried out after the first and second stages of the analysis. After the third stage, the influence of the dynamic impact was estimated. The final calculation results showed that the maximal displacements did not exceed the limit values, and load-bearing capacity of structural members is sufficient. So, the facility satisfies the requirements of designing codes. The most actual dynamic load acted, when one side of the facility stops. The most dangerous static load was an oblique wind. The most unfavorable combination was created, when these two above-described dynamic and static loads coincide and act in the same direction. Thus, the torsion of the facility dominates. Across the facility, the transverse frames take over and carry the acting loads, and the brace system is distributed the longitudinal loads. Therefore, two orthogonal stiffnesses are sufficient.

The system of braces plays a very important role for the designed facility. The model Beam 1D does not express a real mechanical work of the facility, because the braces on the one-dimensional axis of the frames can only deform in the middle plane. Imitation by using the short rigid inserts is not an efficient tool. The models Truss 1D and Plate 2D allow to create and efficiently use two brace levels for the top beam and both columns. Such solutions reflect the real deformation of the mobile facility. So, both models Truss 1D and Plate 2D should be compared.

A general stiffness of the model Plate 2D is more than of the model Truss 1D (Table 5).

Table 5

Comparison of relative longitudinal displacements

\begin{tabular}{|c|c|c|c|}
\hline FEM model & Statics & $\begin{array}{c}\text { Dynamics:both } \\
\text { sides }\end{array}$ & $\begin{array}{c}\text { Dynamics: one } \\
\text { side }\end{array}$ \\
\hline Truss 1D & 0.63 & 0.69 & 0.72 \\
\hline Beam 1D & 0.82 & 0.93 & 0.98 \\
\hline Plate 2D & 0.28 & 0.39 & 0.42 \\
\hline
\end{tabular}

Of course, both models are possible for the practical realization. The next criterion for comparison is the weight, which is about twice lower in case of the model Truss 1D. Therefore, the scheme Truss 1D is more preferable for the economic reason, when the model Plate 2D is more favorable in the structural sense.

\section{Conclusions and recommendations}

To sum up these investigations of complex design of a mobile facility, the following conclusions and recommendations have been made:

1. Investigating original structures of a mobile moving facility, a special algorithm has been created, static and dynamic calculations have been performed, the general stability has been analyzed, and cross sections have been selected on the basis of the limit states. The calculation has been carried out by three stages, three different FEM models have been considered.

2. For the proposed schemes of the mobile facility, the calculation of only a transversal frame is efficient in the preliminary determination of the cross-sectional areas and of the total structural weight. The accuracy of $2-5 \%$ of such results is sufficient for estimating the cost of construction work and determining the preliminary price. For the designing, the analysis of the state of the simplified transverse frame is not enough, because the braces between the frames are very important ones.

3. Static and dynamic analysis of the whole facility in different configurations and with different supports is required. The most important actions on the mechanical state of the facility are the oblique wind and one-side braking.

4. The one-dimensional model Beam 1D does not correspond to the real situation, because of location of braces in one plane. This FEM model is too flexible. We do not recommend to usage it.

5. The FEM models Truss 1D and Plate 2D are appropriate ones in their own manner. The Truss $1 \mathrm{D}$ is about twice as light as the Plate 2D, but it is by $30 \%$ more flexible.

For the realisation of results, an economic analysis is needed, which takes into account the costs of production, mounting and operation of such mobile moving facilities.

\section{References}

1. Song, J. Y.; Woo, J. H. 2013. New shipyard layout design for the preliminary phase and case study for the green field project, Int Jour Naval Archit Ocean Eng 5: 132-146. http://dx.doi.org/10.2478/IJNAOE-2013-0122.

2. Basan, N. P.; Coccola, M. E.; Garcia del Valle, A.; Mendez, C. A. 2019. An efficient MILP-based decomposition strategy for solving large-scale scheduling problems in the shipbuilding industry, Optim and Eng. 20: $1085-1115$. https://doi.org/10.1007/s1 1081-019-09457-y.

3. Coda, H. B.; Paccola, R. R. 2014. A total-Lagrangian position-bases FEM applied to physical and geometrical non linear dynamics of plane frames including semi-rigid connections and progressive collapse, Finite Elem Analysis and Design 91: 1-15. https://doi.org/10.1016/j.finel.2014.07.001.

4. Xue, Q.; Meek, J. L. 2001. Dynamic response and instability of frame structures, Comp Meth App Mech Eng 190: 5233-5242. https://doi.org/10.1016/S0045-7825(01)00166-9.

5. Mamaghani, I. H. P.; Usami, T.; Mizuno, E. 1996. Inelastic large deflection analysis of structural steel members under cycling loading, Eng Struct 18: 659668.

https://doi.org/10.1016/0141-0296(96)00204-0.

6. Samofalov, M.; Cvirka, V. 2010. Mechanical state analysis and an original sequence of calculations of a huge bay arch under static and dynamic actions, Int Conf Modern Build Mater Struc Techn. 2: 1045-1054.

7. Samofalov, M.; Šlivinskas, T. 2009. Stability analysis of steel frames with variable cross-section for sports and entertainment centre, Mechanika 5(79): 5-12. 
8. Marti, P. 2018. Theory of Structures: Fundamentals Framed Structures Plates and Shells. Ernst \& Sohn. $696 \mathrm{p}$.

9. Davidson, B.; Owens, G. W. 2012. Steel Designers Manual. 7th edition. Steel Constr Inst. 1415 p.

10. Akin, J. E.; Mofid, M. 1989. Numerical solution for response of beams with moving mass, ASCE Struc Eng 115: $120-131$. https://doi.org/10.1061/(ASCE)07339445(1989)115:1(120).

11. Esmailzadeh, E.; Ghorashi, M. 1995. Vibration analysis of beams traversed by uniform partially distributed moving masses, Jour Sound Vibr, 184: 9-17. https://doi.org/10.1006/jsvi.1995.0301.

12. Lee, H. P. 1996. The dynamic response of Timoshenko beam subjected to a moving mass, Jour Sound Vibr. 198: 249-256. https://doi.org/10.1006/jsvi.1996.0567.

13. Wang, Z.; Peng, Z.; Liu, C.; Shi, X. 2019. Virtual decoupling of mechanical systems considering the mass effect of resilient links: theoretical and numerical studies, Mech Syst Sign Proc. 123: 443-454. https://doi.org/10.1016/j.ymssp.2019.01.028.

14. Joao, L. S.; Carvalho, R.; Fangueiro, R. 2016. A study on the durability properties of textile membranes for architectural purposes, Proc Eng. 155: 230-237. https://doi.org/10.1016/j.proeng.2016.08.024.

15. Ren, W.; Sneed, L. H.; Yang, Y.; He, R. 2015. Numerical simulation of prestressed precast concrete bridge deck panels using damage plasticity model, Int Jour Conc Struct Mater 9: 45-54. https://doi.org/10.1007/s40069-014-0091-2.

16. Zhang, X.; Peng, J.; Cao, M.; Damjanovic, D.; Ostachowicz, W. 2020. Identification of instantaneous tension of bridge cables from dynamic responses: Strict algorithm and applications, Mech Syst Sign Proc. 142: 106729. https://doi.org/10.1016/j.ymssp.2020.106729.

17. Motwani, P.; Laskar, A. 2019. Influence of excessive end slippage on transfer length of prestressing strands in PC members, Struct. 20: 676-688. https://doi.org/10.1016/j.istruc.2019.05.004.

18. Zhouzhou, X.; Zixue, U.; Zhen, Y.; Junchao, Z. 2020. Research on vehicle-bridge vertical coupling dynamics of monorail based on multiple road excitations, Mechanika 26(4): 301-310. http://dx.doi.org/10.5755/j01.mech.26.4.24399.

19. Saritas, A. 2017. Consistent matrices for steel framed structures with semi-rigid connections accounting for shear deformation and rotary inertia effects, Eng Struct. 137: 194-203.

https://doi.org/10.1016/j.engstruct.2017.01.070.
20. Jin-Jun, L.; Guo-Qiang, L.; Siu-Lai Chan. 2003. A second-order inelastic model for steel frames of tapered members with slender web, Eng Struct. 25: 1033-1043. https://doi.org/10.1016/S0141-0296(03)00043-9.

21. Scofidio, D. 2017. The shed, ARQ (Santiago), 97: Online version ISSN 0717-6996 [accessed 6 Jan. 2021]. Available from Internet: https://scielo.conicyt.cl/scielo.php?script=sci_abstract\& pid=S0717-69962017000300028\&lng=en\&nrm=iso.

\section{T. Astrauskas, M. Samofalov}

\section{INVESTIGATION OF COMPLEX STRUCTURAL DESIGNING OF MOBILE FACILITIES FOR SHIPBUILDING IN LITHUANIAN SEA REGION}

S u m m a r y

In the paper, it is proposed to cover by a mobile moving facility the shipyard open site, in Klaipeda, Lithuania (the EU). The facility of $40 \mathrm{~m}$ span consists of transversal frames, which are arranged by the step of $6.0 \mathrm{~m}$, and a system of braces. Two types of steel frames have been considered: trussed and continuous. The actions are specified according to the design codes (Eurocode 3 ) and climatological data. In dynamic analysis, the longitudinal direction is defined for an inertia action, simulating braking. For calculating, a special algorithm of three stages has been prepared. At the first stage, three calculation schemes of one transversal frame were created. For the proposed schemes of the mobile moving facility, the calculation of only a transversal frame is effective in the preliminary determination of the cross-sectional areas and of the total structural weight. At the second stage, the frames were joined by braces. A preliminary comparison of the calculation results of the models was carried out after the first and second stages of the analysis. At the third stage, the dynamic analysis was performed and the influence of the dynamic impact was estimated. Finally, we compared the calculation results of three different FEM models and chose the most appropriate one. To sum up the investigations, conclusions and recommendations are presented.

Keywords: mobile frames, port facility, shipbuilding, complex structural designing, static and dynamic analysis.

Received March 29, 2021

Accepted June 02, 2021

This article is an Open Access article distributed under the terms and conditions of the Creative Commons Attribution 4.0 (CC BY 4.0) License (http://creativecommons.org/licenses/by/4.0/). 